\section{A NOVEL STATOR DOUBLY FED DOUBLY SALIENT PERMANENT MAGNET BRUSHLESS MACHINE}

K. T. Chau', J. Z Jiang ${ }^{2}$ and Yong Wang

(1) Department of Electrical \& Electronic Enyineering. The University of Hong Kong. Pokfulan Road. Hong Kong (2) Department of Automation, Shanghai University, Shanghai 200072, China

Purpose

Recently, the doubly salient permanent magnet (DSPM) machine has been attractive because of its high power density and high efficiency, but still suffering from limited constant-power speed range and high PM material cost [1],[2]. To solve these problems, the stator doubly fed doubly salient (SDFDS) machine topology has been proposed [3], which replaces the PM material by a do field winding to facilitate flux weakening operation and on-line efficiency optimization. However, this topology inevitably needs high field winding MMF to realize the desired flux weakening, hence degrading its electric loading and power density. In this paper, a novel SDFDS-PM brushless machine topology is proposed, which not only reduces both $P M$ material and field winding MMF significantly, but also offers the distinct advantage of wide constant-power operation range (namely, 4 times the base speed) which is essential for electric vehicle application.

Proposed topology

As shown in Fig. I, the proposed machine consists of two types of stator windings - polyphase armature winding and dc field winding. The polyphase armature winding operates like that for a DSPM machine, whereas the field winding not only works as an electromagnet but also as at tool for flux weakening and/or flux optimization. The novelty of this topology is to purposely add an extra flux path in parallel with each PM pole. If the tield winding MMF reinforces the PM MMF, this extra flux path will assist the effect of flux strengthening. On the other hand, if the field winding MMF opposes the PM MMF, this extra flux path will favor the PM flux leakage. hence amplifying the effect of flux weakening. The principle of operation is illusirated in Fig. 2.

Results

Based on equivalent magnetic circuit approach, the air-gap fluxes in the presence of zero, positive and negative field current can be respectively represented as:

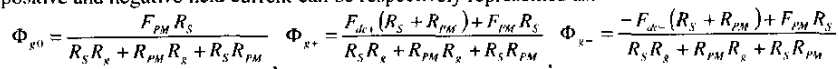

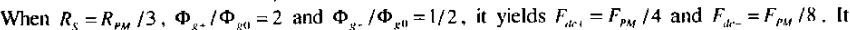
illustrates that a quadruple change in air-gap flux only desires a small change in ficld winding $M M F$ (one-fourth of PM MMF during flux strengthening, and one-eighth during flux weakening), which can he confirmed by finite element analysis as shown in Figs. 3 and 4. Moreover, the corresponding flux linkages against the rotor position are shown in Fig. 5 . Finally, the torque-current characteristic of the proposed machine is shown in Fig. 6 . Detailed simulation and experimental results will be included in the full paper.

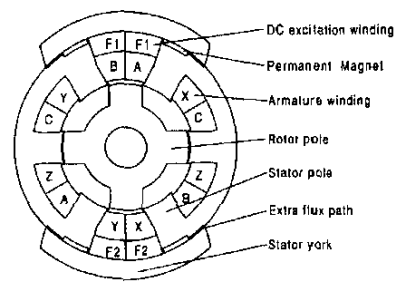

Fig. 1. Proposed machine topology.

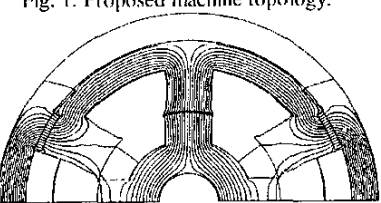

Fig. 3. Distribution under flux strengthening.

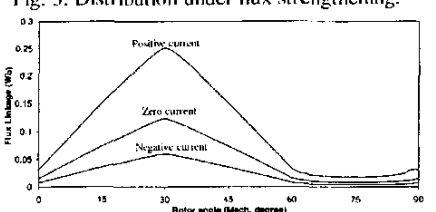

Fig. 5. Flux linkages at various field currents.

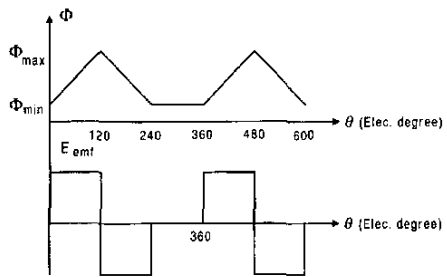

Fig. 2. Principle of operation.

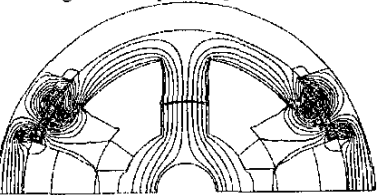

Fig. 4. Distribution under flux weakening.

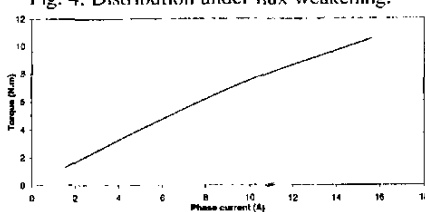

Fig. 6. Developed torque versus phase current. References

[1] Y. Liao, F. Liang and T. A. Lipo, "A novel permanent magnet motor with doubly salient structure," IEEE Trans. Industry Applications, Vol. 31. No. 5, Sept/Oct 1995, pp. 1059-1078.

[2] M. Cheng, K. T. Chau and C. C. Chan, "Design and analysis of a new doubly salient permanent magnet motor," IEEE Trans. Magnetics, Vol. 37, No. 4, July 2001, pp. 3012-3020.

[3] K. T. Chan. M. Cheng and C. C. Chan. "Nonlincar magnetic circuit analysis for a nove stator-doubly-fed doubly-salient machine." Intermag. April 2002, Paper No. AU05. Also IEE Transactions on Magnetics, Vol. 38. No. 5, Sept. 2002, in press. 